\title{
DIFFERENCES IN STYLES OF THINKING 'IN LIGHT OF STERNBERG'S THEORY': A CASE STUDY OF DIFFERENT EDUCATIONAL LEVELS IN SAUDI ARABIA
}

\author{
Nahla Aljojo iti \\ Faculty of Computing and Information Technology, Information Systems Department, King \\ Abdulaziz University (Saudi Arabia) \\ naljojo@kau.edu.sa
}

Received May 2017

Accepted July 2017

\section{Abstract}

People's styles of thinking vary; we seek to understand these differences, to refine our abilities and skills, and find new and useful ways of thinking. To develop this concept, we implement the Sternberg (1997) thinking style inventory (TSI) as part of the learning process. The main idea behind the implementation of this style of thinking is to help people understand themselves, and identify the correct completion of tasks. In this study, we investigate different ways of thinking in various academic disciplines, which may help students find the best potential use of teaching and learning, and realize the best way to develop their true abilities. This paper investigates the thinking styles of 120 female and male students from different educational backgrounds across Saudi Arabia by using an Arabic version of Robert Sternberg's questionnaire to examine their learning performance. In addition, we compare the thinking styles of Saudi Arabian males and females, demonstrating significant differences between the sexes of participants.

Keywords - Thinking, Sternberg, Styles, Inventory, Sex, Learning. 


\section{Introduction}

Thinking is a process by which a student improves through psychological interactions with acquired expertise, developing new cognitive structures, rules, and beliefs (Qatami, 2001). Researchers have described a variety of different thinking styles:

- An up scale process of mental knowledge that involves reorganization of situational elements of a problem in a new way so as to allow the realization of relationships or the solving of problems. This process includes thinking as well as other mental and cognitive processes, including attention, perception, and memory in addition to skills such as classification and conclusion, analysis, synthesis, and comparisons of circular and other arguments (El-Maati, 2005).

- Different styles of thinking define the way that people organize, or consider, their answers and approaches to positive procedures. Importantly, styles of thinking do not refer to the skills used, such as intelligence, but rather to how people choose their thoughts. Analysis of thinking styles is also concerned with how people respond, or choose to respond, to a given occurrence (Kim \& Song, 2012).

This study deals with education in the light of Sternberg's (1997) theory that suggests there are thirteen ways of thinking that fall into five categories. These different forms include the Monarchic, Hierarchic, Anarchic, and Oligarchic styles, that can have Legislative Executive, or Judicial styles. These can have Global or Local styles, including Liberal and Conservative leanings, and be External or Internal in scope (Richmond, Krank \& Cummings, 2006).

The purpose of this paper is to examine the thinking styles of 120 female and male students drawn from different Saudi Arabian educational levels by using the Arabic version of the Sternberg Thinking Style Inventory (TSI) to improve the learning process. This paper also compares male and female thinking styles in Saudi Arabia. 


\section{Literature review}

Literature relevant to this subject is listed here in sequence.

Paivio (1971) wrote about model perception, putting forward an idea called Dual Coding Theory, which assumes the existence of encrypting systems as well as the representation and processing of information. The most important axioms of this theory are the presence of so-called 'representation avatar systems' that specialize in dealing with information, whether it be cognitive, emotional, or behavioral. Two subsystems of independent representation or information processing are also thought to exist, one dealing with non verbal, the other with language. Thus, according to Paivio (1971), there are two different ways that individuals think: verbal, and nonverbal or image-based. Which one depends on the tendencies of the individuals as well as their preferred style of thinking, or cognitive habit, as distinct from the efficient performance of cognitive ability, which is linked to specific cognitive functions (Nigel, 2014).

Harrison and Bramson (1982) proposed a model that implies the existence of five favored methods used by individuals depending on available information, attitude, and the problems they face. This classification is based on mid-term brain control (i.e., right and left patterns), which differ from one another in the treatment and processing of information and depend on performance (i.e., logical versus illogical) and content (i.e., perception of phonetics). Thus, the five distinct kinds of thinking based on the model of Harrison and Bramson (1982) are the Synthesis, Idealistic, Pragmatic, Analytic, and Realistic styles (Golian, 1999).

Following eleven years of research and experimentation, and with the help of the theory of moderation capacity, a Gregorc design tool has been developed for planning the way of thinking used in the self-analysis process. This idea is based on the theory that capacity of the mind channels used to receive information and analysis is more efficient and effective than others (King, 2014).

Gregorc identified four channels to suggest that the environments and natural tendencies of the learner employ one or more of the following methods of thinking: Concrete Sequential; Concrete Random; Abstract Sequential, and; Abstract Random.

The Mindex Profile Theory of perception was proposed by Karl Albrecht (2011), who suggested that the theory of thinking styles is based on processing information in an individual's characteristic way. In other words, one acquires knowledge, organizes ideas, forms a views and opinions, solves problems, and plans and expresses them to others (Albrecht, 2011). This Mindex 
theory of thinking styles recognizes four basic cognitive preferences, of which one is left-brained and concrete, one is right-brained and concrete, one is left-brained and abstract, and one is rightbrained and abstract. Although 20 dimensions have been considered useful, most users are fascinated primarily by these four primary thinking habits (Albrecht, 2011).

To understand and remember these four thinking styles, Albrecht (2011) assigned them simple color-based names. In this scheme, 'blue' thinking is the left-brained mode-of-thought that denotes 'cool' personalities, while 'red' thinking is a right-brained mode-of-thought that corresponds to 'warmer' personalities (Albrecht, 2011). Similarly, Albrecht (2011) gave simple names to other dimensions, the concrete and abstract levels. In this application, concrete, immediate, and results-oriented modes-of-thought are called 'earth' thinking, while imaginary, hypothetical, and conceptual modes are called 'sky' thinking (Albrecht, 2011).

Herrmann (1989) used electroencephalogram (EEG) scans in combination with questionnaires to distinguish four particular modes of thinking, each generally relating to brain structure. To do this, Herrmann (1989) built up a substantial self-evaluation questionnaire that empowers people to comprehend their own style of thinking and inclinations-the Herrmann Brain Dominance Instrument, or HBD (Herrmann, 1989).

Herrmann (1989) also consolidated research on the contrasts between the right and left sides of the brain, with consideration of the Triune brain, to create a figurative model that delineates the idea that every individual essentially has four brains used for thinking and learning (Herrmann, 1989).

Contingent upon which quadrants we connect with, learning procedures can be entirely different. Brain strength prompts thinking-style inclinations, which affect consideration and how we best realize the four styles of thinking, specifically, rational self (the upper or cerebral left brain), safekeeping self (the lower or limbic left brain), feeling self (the lower or limbic right brain), and experimental self (the upper or cerebral right brain) (Herrmann, 1989).

Thinking styles have been used and investigated in different educational settings. Indeed, Sternberg and Grigorenko (2001) suggested that thinking styles can add meaningfully to student capabilities as a tool for educational accomplishment. In particular, outcomes from a secondary school test demonstrated that both legislative and judicial thinking styles implied success in analytical responsibilities, while judicial and executive thinking styles forecast good performance in imaginative responsibilities (i.e., affecting legal task performance positively, and official task 
performance adversely). Outcomes from studies on high school students showed additionally that thinking and reasoning styles could be correlated with student education (Russell. 1999; CanoGarcia \& Hughes, 2000; Sternberg \& Zhang, 2001). In a number of studies by Zhang and coworkers (e.g., Bernardo, Zhang \& Callueng, 2002; Zhang, 2003; Zhang; 2001; Zhang \& Sternberg, 1998) educational success has been linked meaning fully to specific styles of thinking.

The different thinking styles, judicial, hierarchical, conservative, internal, and global, were identified by Zhang and Sternberg (1998) as positively predicting the performance of Hong Kong University students, while local, legislative, liberal, and external styles were negative predictors. In support of these results, Zhang (2001) conducted a study on the internal and hierarchic thinking styles that contribute to them, demonstrating that external, executive, local, liberal, judicial, and legislative thinking styles negatively forecasted scholarly performance in Hong Kong College undergraduates. Moreover, Zhang (2003) went further and discovered that U.S. college undergraduate self-reported GPA's were negatively predicted by both liberal and worldwide deduction styles, while the traditionalist intuition style emphatically predicted selfreported GPAs. In a later study, Zhang (2003) also showed that hierarchic, monarchic, and legal modes of thought positively predicted scholastic performance. Although there are other explanations for good performance, especially in relation to online instruction, these studies show at least that reasoning styles might be good indicators of scholastic performance in online educational situations.

Felder and Silverman (1988) identifies four dimensions in which to categorise the learning styles of individuals; these can be observed independently and illustrate the ways in which individuals prefer to process (active/reflective), perceive (sensing/intuitive), receive (verbal/visual), and understand (sequential/global) information.

Despite the fact that reasoning styles have been connected to instructive settings in a few studies (e.g., Sternberg \& Grigorenko, 1993, 1995, 1997; Zhang, 2003; Zhang; 2001; Zhang \& Sternberg, 1998) little research on thinking styles has been connected to online classes. Richmond et al. (2006) utilized the TSI (Sternberg, 1997) to establish that there were lopsidedly more hierarchic and authoritative scholars in online classes than what is normal. They didn't, in any case, consider whether insight style predicted scholarly accomplishment in online classes. 


\section{Sternberg theory}

Sternberg's (1997) theory of thinking styles led to accepting the alterations about how individuals think, and understanding that most of the thinking styles within the education environment failure led to firmness Sternberg's theory proved to be blessing, especially to teachers; Sternberg's theory helps teachers to understand the student's ability at different levels of Education (Richmond et al., 2006).

Sternberg identified the patterns of thinking and divided them into five categories (jobs, models, levels, scale, orientation) which contain thirteen styles (legislative, executive, judicial, royal, hierarchical, oligarchical, messy, global, local, interior, foreign affairs oriented, liberal, and conservative) (Richmond \& Conrad., 2012). Sternberg has described 13 separate characteristics and five categories that comprise his theory of thinking styles.

- Functions: Includes three methods (Sternberg, 2012) the legislative thinkers who are selfsupported and accomplishing tasks separately, executive thinkers who abide by the rules and regulations used, and Judicialpeople test whether pre-established rules and systems are necessary or valid.

- Forms: In (Sternberg, 2012) theory, this category contains four methods (monarchic, hierarchic, oligarchic, and anarchic): the way in which to get closer to the environment and the challenges and changes it will face, the royal individual who resolves conflicts, whom Sternberg (2012) described as individual and stimulating, who can identify the priorities and know that not all the goals can be achieved, a few individuals who can multi-task and may conflict with the priorities of the organization, and finally individuals living in chaos, who have their own needs that are not in line with existing systems and tend to defend rather than create their own system (Sternberg, 2012).

- Levels: Sternberg (2012) explained the levels as the way they were related to individual requirements in action. This was Sternberg's method of accounting for inspiration within his theory of perceptual self-government. People who have a global level, exposed to problems, are clearly defined. Local individuals, focus on well-defined problems, and they may not be able to understand bigger, more complex problems

- Scope: Defined two characters' styles (Sternberg, 2012):

- "Internal individuals": They desire to work on their own instead of with the team Sternberg 
- "External individuals": They like to work with others and participate in work groups (Richmond et al., 2006).

- Learning: Thought of as a "second stylistic variable", portraying the identity attributes that clarify the routines and guidelines people use in critical thinking (Sternberg, 2012). There are two sorts of learning: liberal individuals question procedures and standards and go past them to take care of issues, while preservationist individuals decide to follow existing guidelines and frequently want to take care of issues in exceptionally organized situations (Sternberg, 2012). While it is vital to talk about the combination of intuition styles delineated by (Sternberg, 2012) it is of more significance to survey the exploration of deduction styles in the scholastic setting.

\section{Method}

This section explores the overall method for the study, which are summarised here:

\subsection{Participants}

To assess thinking styles in Saudi Arabia, 120 students were randomly selected from high schools, intermediate schools and universities participated in this study. There were 72 females $(60 \%)$ and 48 males (40\%). The aggregate number of participants was aged fifteen to twenty-five years old. See Table1.

\begin{tabular}{|l|r|r|r|r|}
\hline Level of educational & Frequency Male & \% Male & Frequency Female & \% Female \\
\hline Undergraduate & 6 & $12.5 \%$ & 45 & $62.5 \%$ \\
\hline High School & 9 & $18.8 \%$ & 22 & $30.6 \%$ \\
\hline Intermediate School & 33 & $68.8 \%$ & 5 & $56.9 \%$ \\
\hline
\end{tabular}

Table 1. Descriptive statistics for demographic Level of educational 


\subsection{Instruments}

Sternberg's Questionnaire consists of 65 questions, of which each of thirteen category styles is represented by five questions. We created website support for Sternberg's theory, and then we applied it to 120 students from different educational levels in Saudi Arabia.

\subsection{Procedure}

Each question had 7 choices; the users checked the number on the Likert scale that best indicated how well the statement described them. When the user entered the test page at the top was an explanation about choices: the student checked 1 if the statement did not fit them at all, or checked 7 if the statement matched them very well, or checked a value that was between to indicate that the statement fit them in different degrees. When the student finished the test, they were shown a result page that had five categories constituting the Sternberg theory, with several methods under each category.

\section{Results}

\subsection{Descriptive Statistics}

As seen in Table 2, Descriptive statistics of the participants (120 students from high school, intermediate school and universities), and the results according to Thinking Styles were as follows:

- Executive was the most frequent in the Functions thinking styles category for female students, representing $44 \%$,

- Hierarchic was the most frequent in the Forms thinking styles category for female students, representing $36 \%$.

- External was the most frequent in the Scope thinking styles category for female students, representing $69 \%$.

- Local was the most frequent in the Levels thinking styles category for female students, representing $66 \%$. 
- Liberal was the most frequent in the learning thinking styles category for female students, representing $60 \%$.

- Judicial was the most frequent of the Functions thinking styles category for male students, representing $50 \%$.

- Hierarchic was the most frequent in the Forms thinking styles category for male students, representing $44 \%$.

- External was the most frequent in the Scope thinking styles category for male students, representing $71 \%$.

- Local and Global had the same frequency in the Levels thinking styles category for male students, representing 54\%.

- Conservative was the most frequent in the learning thinking styles category for male students, representing $77 \%$.

\subsection{Comparison of thinking style of Sternberg Thinking Style Inventory (TSI) for males and females}

The comparison of male and female students' results from the TSI survey are shown in Table 2 and Figure 1. Based on thinking styles frequencies, we defined the female students' thinking styles as Executive, Hierarchic, External, Local and Liberal while the thinking styles of male students was Judicial, Hierarchic, External, Local and Conservative. In other words, female students differed from male students in the Executive vs Judicial, and Liberal vs Conservative Thinking styles. However, both male and female students displayed three of the same Thinking styles (Hierarchic, External, and Local).

Based on the independent sample, test analyses were performed on thirteen thinking styles of Sternberg Wagner Thinking Style Inventory (TSI) for male and female students. In Table 3, $\mathrm{P}=.048$. $<0.05$ for Judicial indicates that male and female students were different in Judicial but shared some similarity in the other thinking styles. 


\begin{tabular}{|c|c|c|c|c|c|c|c|c|}
\hline gender & $\begin{array}{c}\text { Thinking } \\
\text { Styles }\end{array}$ & "Legislative" & "Executive" & "Judicial" & "Global" & "Local" & "Liberal" & "Conservative" \\
\hline \multirow{4}{*}{ Female } & Mean & .42 & .44 & .32 & .40 & .67 & 1.92 & .43 \\
\hline & \begin{tabular}{c|c|} 
Std. \\
Deviation
\end{tabular} & .49 & .50 & .47 & .49 & .47 & 5.57 & .49. \\
\hline & Percent & $42 \%$ & $44 \%$ & $32 \%$ & $40 \%$ & $67 \%$ & $60 \%$ & $43 \%$ \\
\hline & Frequency & 30 & 32 & 23 & 29 & 48 & 43 & 31 \\
\hline \multirow{4}{*}{ Male } & Mean & .27 & .42 & .50 & .54 & .54 & .31 & .77 \\
\hline & \begin{tabular}{c|c|} 
Std. \\
Deviation
\end{tabular} & .45 & .49 & .51 & .50 & .50 & .47 & .42 \\
\hline & Percent & $27 \%$ & $42 \%$ & $50 \%$ & $54 \%$ & $54 \%$ & $31 \%$ & $77 \%$ \\
\hline & Frequency & 13 & 20 & 24 & 26 & 26 & 15 & 37 \\
\hline
\end{tabular}

\begin{tabular}{|c|c|c|c|c|c|c|c|}
\hline gender & $\begin{array}{c}\text { Thinking } \\
\text { Styles }\end{array}$ & "Hierarchic" & "Monarchic" & "Oligarchic" & "Anarchic" & "Internal" & "External" \\
\hline \multirow{4}{*}{ Female } & Mean & .36 & .26 & .35 & .22 & .39 & .69 \\
\hline & $\begin{array}{c}\text { Std. } \\
\text { Deviation }\end{array}$ & .48 & .44 & .48 & .42 & .49 & .46 \\
\hline & Percent & $36 \%$ & $26 \%$ & $35 \%$ & $22 \%$ & $39 \%$ & $69 \%$ \\
\hline & Frequency & 26 & 19 & 25 & 16 & 28 & 50 \\
\hline \multirow{4}{*}{ Male } & Mean & .44 & .35 & .39 & .27 & .44 & .71 \\
\hline & $\begin{array}{c}\text { Std. } \\
\text { Deviation }\end{array}$ & .50 & .48 & .49 & .44 & .50 & .45 \\
\hline & Percent & $44 \%$ & $35 \%$ & $40 \%$ & $27 \%$ & $44 \%$ & $71 \%$ \\
\hline & Frequency & 21 & 17 & 19 & 13 & 21 & 34 \\
\hline
\end{tabular}

Table 2. Descriptive statistics of the male $\&$ female participants according to their thinking styles

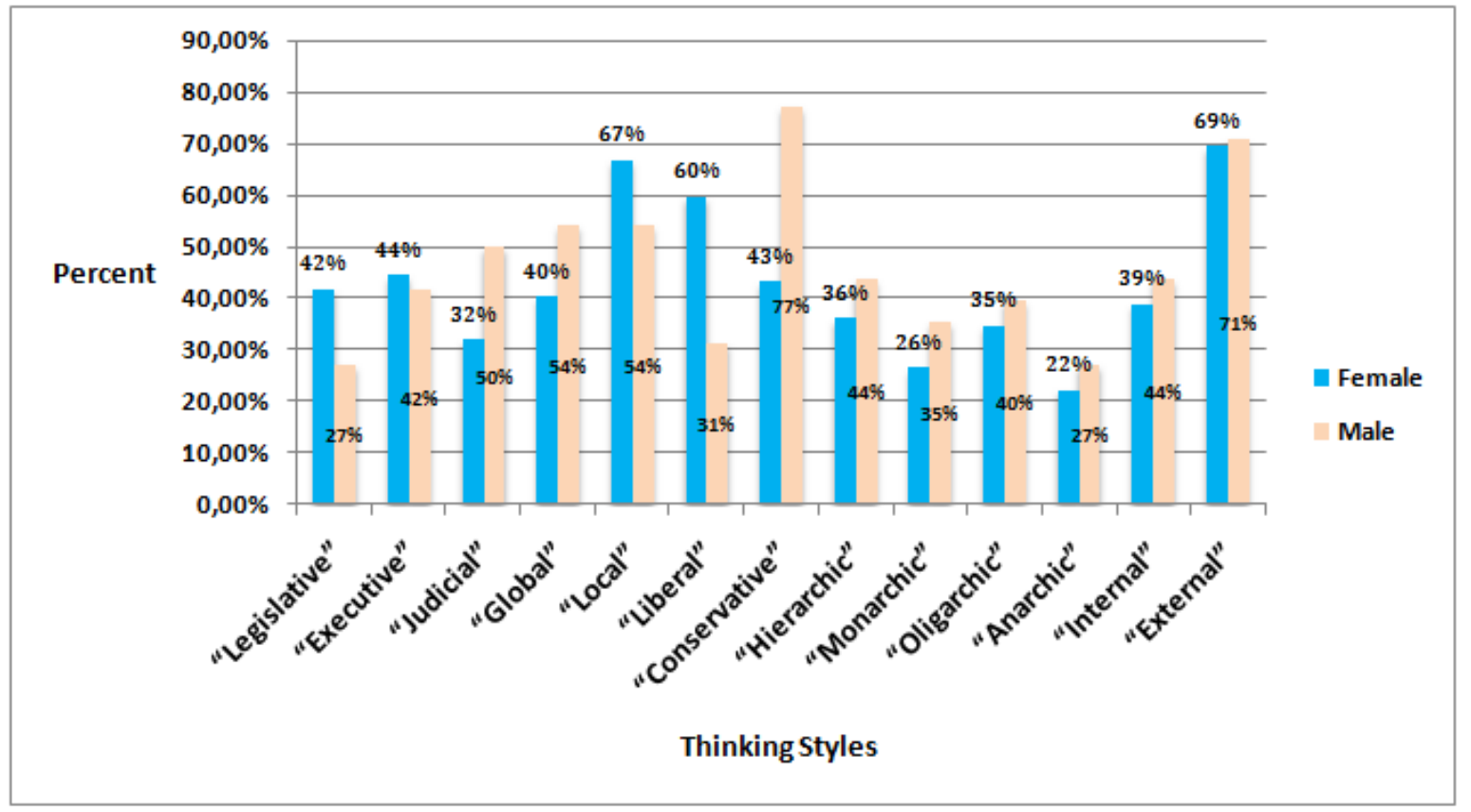

Figure 1. Female Vs Male Thinking Styles 


\begin{tabular}{|l|l|r|r|r|}
\cline { 3 - 5 } \multicolumn{2}{c|}{} & \multicolumn{1}{c|}{$\mathbf{t}$} & \multicolumn{1}{c|}{ df } & Sig. (2-tailed) \\
\hline \multirow{2}{*}{ Legislative } & Equal variance assumed & 1.637 & 118 & .104 \\
\cline { 2 - 5 } & Equal variance not assumed & 1.670 & 107.532 & .098 \\
\hline \multirow{2}{*}{ Jxecutive } & Equal variance assumed & .298 & 118 & .766 \\
\cline { 2 - 5 } & Equal variance not assumed & .299 & 101.179 & .766 \\
\hline \multirow{2}{*}{ Global } & Equal variance assumed & $-2.002-$ & 118 & .048 \\
\cline { 2 - 5 } & Equal variance not assumed & $-1.972-$ & 95.694 & .051 \\
\hline \multirow{2}{*}{ Local } & Equal variance assumed & 1.001 & 118 & .319 \\
\cline { 2 - 5 } & Equal variance not assumed & 1.012 & 104.491 & .314 \\
\hline \multirow{2}{*}{ Liberal } & Equal variance assumed & $-1.227-$ & 118 & .222 \\
\cline { 2 - 5 } & Equal variance not assumed & $-1.255-$ & 108.201 & .212 \\
\hline \multirow{2}{*}{ Conservative } & Equal variance assumed & .599 & 118 & .550 \\
\cline { 2 - 5 } & Equal variance not assumed & .597 & 99.524 & .552 \\
\hline \multirow{2}{*}{ Hierarchic } & Equal variance assumed & $-1.191-$ & 118 & .236 \\
\cline { 2 - 5 } & Equal variance not assumed & $-1.189-$ & 100.193 & .237 \\
\hline \multirow{2}{*}{ Monarchic } & Equal variance assumed & $-.835-$ & 118 & .405 \\
\cline { 2 - 5 } & Equal variance not assumed & $-.829-$ & 98.360 & .409 \\
\hline \multirow{2}{*}{ Oligarchic } & Equal variance assumed & $-1.053-$ & 118 & .294 \\
\cline { 2 - 5 } & Equal variance not assumed & $-1.035-$ & 94.854 & .303 \\
\hline \multirow{2}{*}{ Anarchic } & Equal variance assumed & $-.537-$ & 118 & .592 \\
\cline { 2 - 5 } & Equal variance not assumed & $-.534-$ & 98.746 & .594 \\
\hline \multirow{2}{*}{ Internal } & Equal variance assumed & $-.605-$ & 118 & .546 \\
\cline { 2 - 5 } & Equal variance not assumed & $-.597-$ & 95.923 & .552 \\
\hline \multirow{2}{*}{ External } & Equal variance assumed & $-.527-$ & 118 & .599 \\
\cline { 2 - 5 } & Equal variance not assumed & $-.525-$ & 99.407 & .601 \\
\cline { 2 - 5 } & Equal variance assumed & $-.161-$ & 118 & .872 \\
\cline { 2 - 5 } & Equal variance not assumed & $-.162-$ & 101.559 & .872 \\
\hline
\end{tabular}

Table 3. Test of independent samples

\section{Discussion}

This study covers many important issues regarding the results of the Sternberg Wagner Thinking Style Inventory (TSI). In discussing the results cited in Tables 2, 3 and 4, the following themes were evident:

- The comparison results from the TSI survey for male and female students found that female students differ from male students in the Executive, and Liberal Thinking styles (functions\&learning categories). However, both male and female students showed three of the same Thinking styles (Hierarchic, External, and Local).

- Based on the independent sample, test analyses were performed on thirteen styles of the Sternberg Thinking Style Inventory (TSI) comparing male and female students. Male and female students were different in Judicial but shared some similarity in the other thinking styles. 


\begin{tabular}{|c|c|r|r|r|}
\hline $\begin{array}{c}\text { Categories of thinking } \\
\text { styles }\end{array}$ & $\begin{array}{c}\text { Most Thinking Styles of } \\
\text { female students }\end{array}$ & Percentage & $\begin{array}{c}\text { Most Thinking Styles of } \\
\text { male students }\end{array}$ & Percentage \\
\hline $\begin{array}{c}\text { Functions (legislative, } \\
\text { executive, and Judicial) }\end{array}$ & Executive & $\mathbf{4 4 \%}$ & Judicial & $\mathbf{5 0 \%}$ \\
\hline $\begin{array}{c}\text { Forms (monarchic, } \\
\text { hierarchic, } \\
\text { oligarchic, and anarchic) }\end{array}$ & Hierarchic & $36 \%$ & Hierarchic & $71 \%$ \\
\hline $\begin{array}{c}\text { scope (Internal and } \\
\text { External) }\end{array}$ & External & $69 \%$ & External & $54 \%$ \\
\hline levels (Local and Global) & Liberal & $66 \%$ & Local and Global & $\mathbf{7 7 \%}$ \\
\hline $\begin{array}{c}\text { learning (liberal, } \\
\text { preservationist) }\end{array}$ & $\mathbf{6 0 \%}$ & Conservative & \\
\hline
\end{tabular}

Table 4. Comparison of most thinking styles of between female and male students

(different Thinking Style are highlighted)

\section{Conclusion}

This paper sheds light on the thinking styles of students by using the Sternberg Thinking Style Inventory (TSI) to examine the learning process in an Arabic learning environment. Also, this paper compares male and female thinking styles in Saudi Arabia; the result shows a significant difference between male and female participants.

The Sternberg theory is used to improve and develop the learning process in an Arabic learning environment; the theory leads to understanding the differences in the way people think and it helps teachers to understand the student's ability at different levels of Education.

\section{References}

Albrecht, K. (2011). Mindex theory: Tbinking styles. Available online at: https://www.karlalbrecht.com/mindex/mindextheory.html

Bernardo, A.B., Zhang, L.F., \& Callueng, C.M. (2002). Thinking styles and academic achievement among Filipino students. The journal of Genetic psychology, 163(2), 149-163.

https://doi.org/10.1080/00221320209598674

Cano-Garcia, F., \& Hughes, E.H. (2000). Learning and thinking styles: An analysis of their relationship and influence on academic achievement. Educational Psychology, 20(4), 413-430.

https://doi.org/10.1080/713663755

El-Maati, J. (2005). Distinctive patterns of different personal styles of thinking. Egyptian Journal of Psychological Studies, 15(49), 375-446. 
Felder, R.M. \& Silverman, L.K. (1988). Learning Styles and Teaching Styles in Engineering Education. Engr. Education, 78(7), 674-681.

Golian, L. (1999). Thinking style preferences among academic librarians: Practical tips for effective work relationships. University Library, Florida Gulf Coast University.

Harrison, A.F., \& Bramson, R.M. (1982). Styles of thinking: Strategies for asking questions, making decisions, and solving problems. Anchor Books.

Herrmann, N. (1989). The creative brain. Brain Books, NC: The Ned Herrmann Group.

Kim, S., \& Song, K. (2012). The effects of thinking style based cooperative learning on group creativity. Creative Education, 3(08), 20. https://doi.org/10.4236/ce.2012.38B005

King, J. (2014). What is your dominant thinking style? The co-founder and publisher of CanadaOne.com ${ }^{\circledR}$ and the CEO of BizZone, a web technology company. Available online at: http://www.canadaone.com/ezine/2013/what are your dominant thinking styles.html

Nigel, J. (2014). Dual coding and common coding theories of memory. Supplement to Mental Imagery. Available online at: http://plato.stanford.edu/entries/mental-imagery/theories-memory.html

Paivio, A. (1971). Imagery and verbal processes. New York: Holt, Rinehart.

Qatami, N. (2001). Teaching thinking basic stage. Oman: Dar thought Printing and Publishing.

Richmond, A.S., \& Conrad, L. (2012). Do thinking styles predict academic performance of online learning?. International Journal of Technology in Teaching and Learning, 8(2).

Richmond, A.S., Krank, H.M., \& Cummings, R. (2006). A brief research report: Thinking styles of online distance education students. International Journal of Technology in Teaching and Learning, 2(1), 58-64.

Russell, T.L. (1999). The No Significant Difference Phenomenon. Raleigh, NC: North Carolina State University.

Sternberg, R.J. (1997). Thinking styles. New York: Cambridge University Press. https://doi.org/10.1017/CBO9780511584152

Sternberg, R.J. (2012). The assessment of creativity: An investment-based approach. Creativity research journal, 24(1), 3-12. https://doi.org/10.1080/10400419.2012.652925 
Sternberg, R.J., \& Grigorenko, E.L. (1993). Thinking styles and the gifted. Roeper Review, 16(2), 122-130. https://doi.org/10.1080/02783199309553555

Sternberg, R.J., \& Grigorenko, E.L. (1995). Styles of thinking in the school 1. European journal for bigh ability, 6(2), 201-219. https://doi.org/10.1080/0937445940060211

Sternberg, R.J., \& Grigorenko, E.L. (1997). Are cognitive styles still in style?. American psychologist, 52(7), 700. https://doi.org/10.1037/0003-066X.52.7.700

Sternberg, R. J., \& Grigorenko, E. L. (2001). A capsule history of theory and research on styles. In R. J. Sternberg \& L.F. Zhang (Eds.), Perspectives on thinking, learning, and cognitive styles. Mahwah, NJ: LEA. University.

Sternberg, R.J., \& Zhang, L. (2001). Perspectives on thinking, learning, and cognitive styles. The educational psychology series (pp. 197-226). Mahwah, NJ: Lawrence Erlbaum.

Zhang, L.F. (2001). Do thinking styles contribute to academic achievement beyond self-rated abilities?. Journal of Psychology, 135(6), 621-637. https://doi.org/10.1080/00223980109603724

Zhang, L.F., \& Sternberg, R.J. (1998). Thinking styles, abilities, and academic achievement among Hong Kong University students. Educational Research Journal, 13(1), 41-62.

Zhang, W.X. (2003). Nanoscale iron particles for environmental remediation: An overview. Journal of nanoparticle Research, 5(3), 323-332. https://doi.org/10.1023/A:1025520116015

Published by OmniaScience (www.omniascience.com)

Journal of Technology and Science Education, 2017 (www.jotse.org)

\section{(a)}

SORERIGHISRESERVED

Article's contents are provided on an Attribution-Non Commercial 3.0 Creative commons license. Readers are allowed to copy, distribute and communicate article's contents, provided the author's and JOTSE journal's names are included. It must not be used for commercial purposes. To see the complete licence contents, please visit http://creativecommons.org/licenses/by-nc/3.0/es/ 